Available online on 15.08.2020 at http://jddtonline.info
Open Access to Pharmaceutical and Medical Research
undestricted non-commercial use, provided the original work is properly cited

Open $\odot$ Access

Research Article

\title{
Pharmacological Modeling and Study for Antidiabetic Activity of Praecitrullus fistulosus Leaves Extracts
}

\author{
Ashutosh Tiwari, C.K Tyagi, Harish Pandey, Sunil K Shah* \\ Department of Pharmacology, College of Pharmacy, Sri Satya Sai University of Technology \& Medical Sciences, Sehore, Madhya Pradesh, India
}

\begin{abstract}
Phytochemical and pharmacological investigations of leaves of Praecitrullus fistulosus for the antidiabetic activity have been done in our research work encompassed in depth and systematic screening of plant leaves and further extraction, characterization and bioevaluation. The research was envisaged for antidiabetic activity of different extracts procured by successive extraction methods and to find out or isolate the most possible active compounds from the active extracts showing the best activity. The antidiabetic activity of all extracts has been evaluated by STZ induced diabetes. The isolated compounds have been evaluated by in-vitro and in-vivo models. The alcohol soluble extractives values were found to be higher than water soluble extractive value. Alcohol being a moderately non polar solvent, able to extract polar and non-polar components yields higher extractive value. The ethanol extract shows significant enhancement in glucose tolerance in glucose fed hyperglycemic normal rats and produced a marked decrease in blood glucose levels at $200 \mathrm{mg} / \mathrm{kg}$ and $400 \mathrm{mg} / \mathrm{kg}$ body weight in streptozotocin-diabetic rats after 21 days treatment.
\end{abstract}

Keywords: Praecitrullus fistulosus, Streptozotocin and Glibenclamide, diabetes, Pharmacological Evaluation

Article Info: Received 09 June 2020; Review Completed 11 July 2020; Accepted 17 July 2020; Available online 15 August 2020

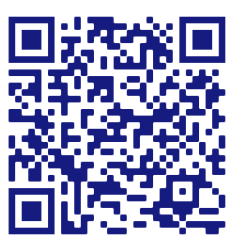

\section{Cite this article as:}

Tiwari A, Tyagi CK, Pandey H, Shah SK, Pharmacological Modeling and Study for Antidiabetic Activity of Praecitrullus fistulosus Leaves Extracts, Journal of Drug Delivery and Therapeutics. 2020; 10(4-s):13-16 http://dx.doi.org/10.22270/jddt.v10i4-s.4276

Dr. Sunil Kumar Shah, Department of Pharmaceutics, College of Pharmacy, Sri Satya Sai University of Technology \& Medical Sciences, Sehore, Madhya Pradesh, India

\section{INTRODUCTION}

Diabetes mellitus is a metabolic disorder characterized by a loss of glucose homeostasis, with disturbances of carbohydrate, fat, and protein metabolism resulting from defects in insulin secretion, insulin action, or both. ${ }^{1}$ It is one of the common metabolic disorders with micro and macro vascular complications that results insignificant morbidity and mortality. It is considered as one of the five leading causes of death in the world. ${ }^{2}$ Antioxidants have been shown to prevent the destruction of $\beta$-cells by inhibiting the peroxidation chain reaction and thus they may provide protection against the development of diabetes. ${ }^{3}$ The worldwide prevalence of diabetes for all age groups was estimated to be $2.8 \%$ in 2000 and it is projected to be $5.4 \%$ in 2025. Currently available therapies for diabetes include insulin and various oral antidiabetic agents such as sulfonylureas, biguanides, $\alpha$-glucosidase inhibitors and glinides. Despite considerable progress in the treatment of diabetes by oral hypoglycaemic agents, search for newer drugs continues because the existing synthetic drugs have several limitations and harmful effects. In the Indian traditional system of medicine several drugs of plant, mineral, and animal origin are described for their antidiabetic properties. There is an increasing demand by patient to use the natural product with antidiabetic activity. Medicinal and herbal plant products are traditionally used from long ago in many countries for the treatment of diabetes mellitus. So the traditional herbal medicines are mainly used which are obtained from plants, it plays important role in the management of diabetes mellitus. ${ }^{4}$ Herbal products or plant products are rich in phenolic compounds, favonoids, terpenoids, coumarins, and other constituents which show reduction in blood glucose levels. ${ }^{5}$ Several species of herbal drugs have been described in the scientific and popular literature as having antidiabetic activity. Due to their perceived effectiveness, fewer side effects in clinical experience and relatively low costs, herbal drugs are prescribed. 6

Praecitrullus fistulosus is reported to contain polyphenols, flavonoids, ascorbic acid, tannin, alkaloid, saponin, phytosterol, diterpines, thiamin, and carotene, proteins, carbohydrates and cardiac glycosides. As per the literature review, it has been observed that Praecitrullus fistulosus is listed among the various medicinal plants widely been used 
as an antimicrobial, antihelmintic, antioxidant and in treatment of diabetes mellitus. Sometimes used for gastric problems, appetizer, dyspepsia, weakness and colic in stomach and taken for blood pressure.Despite the rich presence of antioxidant principles and traditional use of Praecitrullus fistulosus leaves, systematic and scientific studies are lacking to delineate the antidiabetic activity of the plant leaves and it effect of hyperglycemia induced oxidative stress. ${ }^{7-11}$ For resolving the problem of Diabetes mellitus, proposed a study in which plant Praecitrullus fistulosus has been selected for the antidiabetic activity.

\section{MATERIAL AND METHODS}

The leaves of Praecitrullus fistulosus were collected and the material was authenticated and identified. The correctly identified plant leaves were washed thoroughly in tap water, shade dried at room temperature for 10 days, coarsely powdered, and the powder was passed through sieve No.60 and used for extraction. This was extracted with different solvents in order to their increasing polarity to get the correct and dependable retention factor. Drug was subjected to extraction with ethanol $(90 \%)$ as well as methanol in soxhlet apparatus, the extraction was completed in 25 cycles for two different solvents i.e. ethanol and methanol respectively. The extracts were dried \& stored in dark place.

Experimental animals Wistar Albino rats of either sex (150 to $200 \mathrm{~g}$ ) were purchased from the CPCSEA approved vendor and maintained at Animal House of the Institute, under standard laboratory conditions. In our studies we selected $1 / 10$ th and $1 / 5$ th dose i.e. 200 and $400 \mathrm{mg} / \mathrm{kg}$ dose (OECD Guideline 2001).12 Doses equivalent to $200 \mathrm{mg}$ and $400 \mathrm{mg}$ of the crude drug per $\mathrm{kg}$ body weight were calculated, and suspended in $1 \% \mathrm{w} / \mathrm{v}$ Tween 80 solutions for the experiment.

Oral Glucose Tolerance Test: A method called Normal Glucose Oral Glucose Tolerance Test [NG-OGTT] is chosen for the effective analysis of drug so as to reduce the usage of a greater number of animals. The glycemic levels of rats withheld from food and water, had been determined and then was indeed administered the extract and standard. The animals had been divided into respective groups of 6 rats in each. Solutions of control, standard and the test samples ( $200 \& 400 \mathrm{mg} / \mathrm{kg}$ ) had been administered orally. The blood glucose levels had been determined in the following pattern: $0 \mathrm{~min}$ and $30 \mathrm{~min}$ to access the effect of test samples on normal blood glucose rats. The rats were then administered orally with $2 \mathrm{~g} / \mathrm{kg}$ glucose and the glucose levels were determined at 60, 90, 120, 150 and 180 min after glucose load. Blood was collected from the tip of the tail vein and fasting blood glucose level was calculated utilizing single touch glucometer (Accu check active) which was designed based on the glucose oxidase technique (Chattopadhyay, 1999). ${ }^{13}$

Group 1: received 1\% w/v Tween 80 solution $(5 \mathrm{ml} / \mathrm{kg}$ body weight)

\section{Group 2: received Glibenclamide $5 \mathrm{mg} / \mathrm{kg}$ body weight}

Group 3: Treated with ethanol extract of Praecitrullus fistulosus (200 mg/kg body weight) Group 4: Treated with ethanol extract of Praecitrullus fistulosus $(400 \mathrm{mg} / \mathrm{kg}$ body weight) Group 5: Treated with methanol extract of Praecitrullus fistulosus (200 mg/kg body weight) Group 6: Treated with methanol extract of Praecitrullus fistulosus ( $400 \mathrm{mg} / \mathrm{kg}$ body weight)

\section{Streptozotocin (Stz) Induced Diabetes In Rats:}

After fasting 18 hours, the rats were injected intraperitoneal injection through tail vein with a single dose of 50 $\mathrm{mg} / \mathrm{kg}$ Streptozotocin, dissolved in freshly prepared .1 M citrate buffer ( $\mathrm{pH}$ 4.5) immediately before use. After injection, the rats had free access to food and water and were given $5 \%$ glucose solution to drink overnight to counter hypoglycemic shock. The diabetes was confirmed by estimating the blood glucose level after 72 hours by glucometer based on glucose oxidation method. Rats having blood glucose level more than $250 \mathrm{mg} / \mathrm{dl}$ were selected for further study (Jaiswal et al., 2014, Edwin et al., 2003, Chattopadhyay et al., 1997).14-16

Experimental Design: In order to assess the anti-diabetic activity, the animals were divided in fifteen groups of six animals in each group.

\section{Group 1: Normal control rats $(0.9 \% \mathrm{NaCl}$ treated $)$}

Group 2: Diabetic control, STZ -treated rats $(50 \mathrm{mg} / \mathrm{kg}$ body weight)

Group 3: Treated with ethanol extract of Praecitrullus fistulosus (200 mg/kg body weight) Group 4: Treated with ethanol extract of Praecitrullus fistulosus $(400 \mathrm{mg} / \mathrm{kg}$ body weight) Group 5: Treated with methanol extract of Praecitrullus fistulosus (200 mg/kg body weight) Group 6: Treated with methanol extract of Praecitrullus fistulosus (400 mg/kg body weight) Group 7: Standard drug (Glibenclamide) treated rats (5 $\mathrm{mg} / \mathrm{kg}$ body weight)

The test drug and reference drug was administered orally at two dose level for a period of 21 days from starting day of diabetes (Yasodamma et al., 2013, Verma et al., 2013). ${ }^{17-18}$ The blood was withdrawn by tail vein puncturing method. The samples of blood were obtained just before inducing diabetes and after drug administration on 3rd, 7th, 14th and 21st day. Blood glucose levels were determined by using glucometer (Rahar et al., 2011). ${ }^{19}$

\section{RESULTS AND DISCUSSION}

The total ash content was 5 times greater than acid insoluble ash, the presence of calcium oxalate crystals or acid soluble inorganic matter. The water and volatile content of a crude drug were determined by test for loss on drying ${ }^{20}$. In our investigation the percentage yield of loss on dying was found to be $6.71 \%(\mathrm{w} / \mathrm{w})$. Extractive values are chiefly used for the determination of exhausted or adulterated drug. The alcohol soluble extractives values were found to be higher than water soluble extractive value. Alcohol being a moderately non polar solvent, able to extract polar and nonpolar components yields higher extractive value.

Table 1: Determination of Physicochemical Parameters

\begin{tabular}{|c|c|c|}
\hline S. No. & Determination & \% ash content \\
\hline 1 & Total ash & $12.03 \pm 0.03$ \\
\hline 2 & Acid insoluble ash & $2.83 \pm 0.02$ \\
\hline 3 & Water soluble ash & $4.86 \pm 0.21$ \\
\hline 4 & Alcohol soluble extract value & $5.20 \pm 0.21$ \\
\hline 5 & Water soluble extract value & $3.80 \pm 0.04$ \\
\hline 6 & Loss on drying & $6.71 \pm 0.03$ \\
\hline
\end{tabular}




\section{Oral Glucose Tolerance Test}

Ethanol extracts (EA) at the dosage levels of 200 \& $400 \mathrm{mg} / \mathrm{kg}$ body weight shown significant hypoglycemic effect in overnight fasted normal rats. Methanol extracts (MT) also shown significant activity in treated rats as compared to normal rats, but the effect was comparatively lesser than ethanol extract 21 .

Table 2: Effect of different extracts on oral glucose tolerance test in normal rats

\begin{tabular}{|c|c|c|c|c|c|c|c|c|}
\hline \multirow[b]{2}{*}{$\begin{array}{l}\text { Group } \\
\text { No. }\end{array}$} & \multirow[b]{2}{*}{$\begin{array}{c}\text { Test sample } \\
\text { (mg/kg) }\end{array}$} & \multicolumn{7}{|c|}{ Blood glucose levels (mg/dL) } \\
\hline & & 0 min & $30 \mathrm{~min}$ & $\begin{array}{c}\text { 60min } \\
\text { (glucose } \\
\text { load) }\end{array}$ & $90 \mathrm{~min}$ & 120 & 150min & 180min \\
\hline I & Normal Contro & $81.43 \pm 3.70$ & $81.80 \pm 1.31$ & $81.38 \pm 2.96$ & $184.10 \pm 4.12$ & $154.05 \pm 3.49$ & $144.05 \pm 3.49$ & $138.26 \pm 3.60$ \\
\hline II & Standard & $82.54 \pm 3.17$ & $69.21 \pm 3.90^{*}$ & 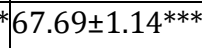 & * $153.28 \pm 5.20^{*}$ & *117.28 $16.20^{* *}$ & $92.98 \pm 5.19^{* * *}$ & $67.38 \pm 2.12^{* * *}$ \\
\hline III & ET $200 \mathrm{mg} / \mathrm{kg}$ & $80.23 \pm 2.70$ & $72.20 \pm 2.11^{* *}$ & 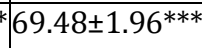 & * $162.30 \pm 4.32$ & $132.04 \pm 2.49^{* *}$ & $120.16 \pm 3.60^{\text {*** }}$ & $* 90.56 \pm 2.60^{* * *}$ \\
\hline IV & ET $400 \mathrm{mg} / \mathrm{kg}$ & $81.33 \pm 5.70$ & $69.30 \pm 1.61^{* *}$ & 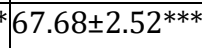 & * $155.10 \pm 4.12$ & $122.05 \pm 3.49^{* * *}$ & *108.46 $\pm 5.50^{* * *}$ & $* 81.56 \pm 6.50^{* * *}$ \\
\hline $\mathbf{V}$ & MT $200 \mathrm{mg} / \mathrm{kg}$ & $81.33 \pm 3.40$ & $79.23 \pm 1.51^{*}$ & $76.18 \pm 1.26^{*}$ & $169.30 \pm 7.12$ & $151.20 \pm 7.19$ & $146.16 \pm 1.60$ & $138.16 \pm 1.60$ \\
\hline VI & MT $400 \mathrm{mg} / \mathrm{kg}$ & $81.13 \pm 8.40$ & $76.40 \pm 5.21 *$ & $72.58 \pm 1.56^{* *}$ & $165.10 \pm 7.12$ & $141.23 \pm 8.19^{* *}$ & $135.26 \pm 3.60^{* *}$ & $133.16 \pm 3.60^{* *}$ \\
\hline
\end{tabular}

\section{Streptozotocin Induced Antidiabetic Activity}

The induction of diabetes with streptozotocin increases the blood glucose level significantly $(\mathrm{p}<0.001)$ in group II rats as compared to normal rats. In 21 day study glibenclamide the standard drug restored the blood glucose highly significant with the $p<0.001$ in 14 days whereas ethanol extract $(200$ \& $400 \mathrm{mg} / \mathrm{kg}$ ) reduced the glucose level significant with the $p<0.01 \& p<0.001$. Methanol extracts had significant effects $(p<0.01)$ on 14 th and 21 st days, but the effect was comparatively lesser than ethanol extract.

Table 3: Effect of different extracts on blood glucose level in streptozotocin induced diabetic rats

\begin{tabular}{|c|c|c|c|c|c|c|}
\hline \multirow{3}{*}{$\begin{array}{c}\text { Group } \\
\text { No. }\end{array}$} & \multirow[b]{3}{*}{ Group } & \multicolumn{5}{|c|}{ Blood Sugar level } \\
\hline & & \multicolumn{5}{|c|}{ Long Term Study (Days) } \\
\hline & & $\begin{array}{c}\text { Before } \\
\text { inducing } \\
\text { Diabetes }\end{array}$ & 3 & 7 & 14 & 21 \\
\hline I & Normal control & $80.3 \pm 0.46$ & $82.2 \pm 0.17$ & $81.4 \pm 1.7$ & $81.9 \pm 0.57$ & $80.11 \pm 0.18$ \\
\hline II & Diabetic control & $82.4 \pm 0.81$ & $242.7 \pm 1.79$ & $273.8 \pm 1.53$ & $268.3 \pm 4.04^{* * *}$ & $298.1 \pm 0.22^{* * *}$ \\
\hline III & Ethanol extract $(200 \mathrm{mg} / \mathrm{kg})$ & $84.27 \pm 3.09$ & $243.4 \pm 4.05$ & $216.2 \pm 2.39^{* * *}$ & $200.8 \pm 2.08^{* * *}$ & $196.2 \pm 0.29^{* * *}$ \\
\hline IV & Ethanol extract (400 mg/kg) & $83.78 \pm 1.09$ & $241.6 \pm 4.09$ & $205.2 \pm 4.75^{* * *}$ & $193.6 \pm 5.02^{* * *}$ & $175.3 \pm 0.82^{* * *}$ \\
\hline $\mathbf{V}$ & Methanol $(200 \mathrm{mg} / \mathrm{kg})$ & $83.4 \pm 0.94$ & $242.6 \pm 1.76$ & $218.9 \pm 3.19$ & $214.8 \pm 2.99^{* *}$ & $211.6 \pm 1.30^{* *}$ \\
\hline VI & Methanol extract $(400 \mathrm{mg} / \mathrm{kg})$ & $78.4 \pm 0.22$ & $240.6 \pm 1.39$ & $214.2 \pm 3.18$ & $211.8 \pm 2.28^{* *}$ & $210.6 \pm 2.210^{* * *}$ \\
\hline VII & Glibernclamide (5 mg/kg) & $82.25 \pm 0.97$ & $240.8 \pm 2.54$ & $192.4 \pm 3.32^{* *}$ & $166.3 \pm 1.47^{* * *}$ & $161.8 \pm 0.34^{* * *}$ \\
\hline
\end{tabular}

Where- ${ }^{*} \mathrm{p}<0.05,{ }^{* *} \mathrm{p}<0.01,{ }^{* * *} \mathrm{p}<0.001$ compared with diabetic control vs treated groups

The ethanol extract produced a marked decrease in blood glucose levels at $200 \mathrm{mg} / \mathrm{kg}$ and $400 \mathrm{mg} / \mathrm{kg}$ body weight in streptozotocin-diabetic rats after 21 days treatment 22,23 . The antidiabetic effect Praecitrullus fistulosus may be due to increased release of insulin from the existing $\beta$-cells of pancreas similar to that observed after glibenclamide administration.

\section{CONCLUSION}

The present investigation comprises of the phytochemical and pharmacological investigations of leaves of Praecitrullus fistulosus for the antidiabetic activity. In preliminary phytochemical assessment, phytoconstituents like carbohydrate, glycosides, alkaloids, phytosterol, triterpinoids, amino acid, phenolic compound, flavonoids ISSN: 2250-1177 and saponins were showed positive tests in the different extracts. In present study, the ethanol extract of Praecitrullus fistulosus produced a marked decrease in blood glucose levels at $200 \mathrm{mg} / \mathrm{kg}$ and $400 \mathrm{mg} / \mathrm{kg}$ body weight in streptozotocin-diabetic rats after 21 days treatment. The antidiabetic effect may be due to increased release of insulin from the existing $\beta$-cells of pancreas similar to that observed after glibenclamide administration. In conclusion, the results of part of the study of selected topic demonstrate that Praecitrullus fistulosus plant leaves have good antidiabetics activity and it opens a new path for further research to continue work in this field so that herbal products or medicines could be brought in market for the benefit of society. 


\section{REFERENCES}

1. Imam K. Clinical features diagnostic criteria and pathogenesis of diabetes mellitus. Journal of Advances in Experimental Medicine and Biology 2012; 771:340-355

2. Ahmed M F, Kazim S F, Ghori S S, Mehjabeen S S, Ahmed S R, Ali S M, Ibrahim M. Antidiabetic activity of Vinca rosea extracts in alloxan-induced diabetic rats. International Journal of Endocrinology 2010; 1 - 6

3. Rajaram K. Antioxidant and antidiabetic activity of Tectona Grandis Linn in alloxan induced albino rats. Asian Journal of Pharmaceutical and Clinical Research 2013; (6)3:174-177

4. Patel K, Srinivasan K. Plant foods in the management of diabetes mellitus: vegetables as potential hypoglycemic agents. Journal Nahrung Food 1997; 41:68-74.

5. He C N, Wang C L, Guo S X. Study on chemical constituents in herbs of Anoectochilus roxburghii. China Journal of Chinese Materia Medica 2005; 30:761-776

6. Shah K., Garg G., Jhade D., Pandey H., Ficus racemosa linn: Its potentials food security and rural medicinal management, J. Pharm. Sci. \& Res. 2016; 8(5):317-322

7. Verspohl E J. Recommended testing in diabetes research. Planta Medica 2002; 68:581- 590

8. Khalid G, Bashir AG, Seema A, Khan M, Showkat AD, Mohammad YD and Mudasir AT: Antidiabetic activity of Artemisia amygdalina Decne in streptozotocin induced diabetic rats. BioMed Research International 2014; 1-10

9. Gautam S, Singh P and Shivhare Y: Praecitrullus fistulosus A Miraculous Plant. Asian Journal of Pharmacy and Technology 2011; 1(1):9-12

10. Gautam S, Singh P and Shivhare Y: Anthelmintic potential of Praecitrullus fistulosus (fruits). International Journal of Drug Discovery and Herbal Research 2011; 1(2):104-105

11. Gautam S and Shivhare Y: Phytochemical screening and antioxidant potential of Praecitrullus fistulosus. Journal of Advanced Pharmacy Education \& Research 2011; 1(5):238242

12. Karandikar A, Prasath G S and Subramanian S: Evaluation of antidiabetic and antioxidant activity of Praecitrullus fistulosus in STZ induced diabetic rats. Research Journal of Pharmacy and Technology 2014; 1(5):238-242
13. OECD Guideline for testing of chemicals Acute Oral Toxicity Acute Toxic Class Method 2001.

14. Chattopadhyay R R. A comparative evaluation of some blood sugar lowering agents of plant origin. Journal of Ethnopharmacology 1999; 67:367-372

15. Jaiswal J, Bhardwaj H, Srivastava S, Gautam H, Sharma S, Rao C V. Anti-diabetic activity of methanolic extract of calotropis gigantea seeds on STZ induced diabetic rats. International Journal of Pharmacy and Pharmaceutical Sciences 2014; 6(1):254-257

16. Edwin E. Anti-hyperglycemic activity of Passiflora mollissima bailey. Indian Journal of Pharmaceutical Sciences 2007; 69(4):570-571

17. Chattopadhyay S. Animals in experimental diabetes mellitus. Indian journal of experimental biology 1997; 35:1141-1145.

18. Kushwaha S, Shah S.K, Patel N., Tyagi C.K., Effects of hydroalcoholic extract of Allium sativum on STZ induce hyperglycemia, The Pharma Innovation Journal 2016; 5(8):106-110.

19. Yasodamma S, Shanthi S K, Alekhya C. anti-diabetic activity of Sebastiania chameleon Muell leaf extracts in alloxan induced diabetic albino rats. International Journal of Pharmacy and Pharmaceutical Sciences 2013; 5(3):577-583.

20. Verma V K, Sarwa K K, Zaman K. Anti-hyperglyceimic properties of Swertia chirayita and Andrographis paniculata plant extracts in streptozotocin induced diabetic rats. International Journal of Pharmacy and Pharmaceutical Sciences 2013; 5(3):305-31.

21. CK Tyagi, Pawan Porwal, Neeraj Mishra, Amit Sharma, A Chandekar, R Punekar, VT Punniyakoyi, Ajay Kumar, Durgadas Anghore, Antidiabetic Activity of the Methanolic Extracts of Thuja occidentalis Twings in Alloxan-induced Rats, Current Traditional Medicine 2019; 5(2):1-10.

22. Rahar S, Swami G, Nagpal N, Nagpal M A, Singh G S. Preparation, characterization, and biological properties of $\beta$ glucans. Journal of Advanced Pharmaceutical Technology \& Research 2011; (2):94-103. 